\title{
RELIGIÃO E POLÍTICA EM CONFLITO: Paulo Stuart Wright e o golpe de 1964
}

\author{
Márcio Ananias Ferreira Vilela*
}

\begin{abstract}
RESUMO: Neste artigo procuramos compreender as implicações da atuação política e religiosa de Paulo Stuart Wright, atuação que a partir do Golpe civil e militar de 1964 sofreu forte reação de setores majoritários da Igreja Presbiteriana do Brasil, que passaram a enxergá-lo como ameaça à comunidade religiosa e à sociedade. Esse momento foi marcado por intenso conflito político no Brasil que contribuiu para a expulsão desse personagem da Igreja, para que tivesse seu mandato de deputado estadual por Santa Catarina cassado, para ser exilado e viver na clandestinidade e, posteriormente, já na década de 1970, ser assassinado pelos órgãos de repressão. Trajetória que em muito representa a de outros personagens da história recente do Brasil.
\end{abstract}

PALAVRAS-CHAVES: Trajetória; Repressão; Igreja.

\section{Religion and politics in conflict: Paul Stuart Wright and the 1964 coup}

\begin{abstract}
In this article, we seek to understand the implications of Paulo Stuart Wright's political and religious action. Beginning with the civil and military coup of 1964, it suffered a strong reaction from majority sectors in the Presbyterian Church of Brazil that started to perceive him as a threat to the religious community and to society itself. The following period was marked by an intense political conflict in Brazil. This contributed for the person in question to be expelled from the Church, have his mandate as a state representative for Santa Catarina impeached, be exiled, live in clandestinity and, later on in the 1970s, be murdered by the organs of repression. Thus, his trajectory bears many similarities to those of others who marked the recent history of Brazil.
\end{abstract}

KEYWORDS: Trajectory; Repression; Church; Paul Stuart Wright.

\section{Religión y política en conflicto: Paul Stuart Wright y el golpe de 1964}

RESUMEN: En este artículo tratamos de entender las implicaciones de la acción política y religiosa de Paulo Stuart Wright, desde el golpe civil y militar de 1964, cuando sufrió una fuerte reacción de los principales sectores de la Iglesia Presbiteriana de Brasil que le veían como una amenaza a la comunidad religiosa y a la sociedad. Dicho momento se caracteriza por un intenso conflicto político en Brasil, que contribuyó para su expulsión de la Iglesia, para que su mandato de diputado del estado de Santa Catarina fuera sometido a juicio político, para ser exiliado y vivir en la clandestinidad y más tarde, ya en la década de 1970, ser asesinado por los órganos de represión. Su trayectoria simboliza la de otros personajes de la historia reciente de Brasil.

PALABRAS-CLAVE: Trayectoria; Represión; Iglesia; Paul Stuart Wright.

\footnotetext{
*Doutor em História pela Universidade Federal de Pernambuco, e professor no Colégio de Aplicação - UFPE. Email:ananiasvilela@ hotmail.com.
} 


\section{Breves marcas de uma sociedade}

Em nossa escrita, o Golpe de 1964 e a instituição da ditadura são compreendidos a partir da relação entre setores da sociedade civil e os militares. Os estudos sobre as sociedades e seus regimes autoritários e ditatoriais têm-se renovado nos últimos anos dentro dessa perspectiva. Para o caso do Brasil, pode-se destacar o trabalho de Angela de Castro Gomes, que na década de 1980 ofereceu uma nova leitura sobre o populismo do governo de Getúlio Vargas, até então compreendido por meio da simples manipulação das massas e de sua repressão. A historiadora mostrou como havia interesses compartilhados entre o Estado e os trabalhadores, o que proporcionou o estabelecimento de apoios e compromissos (GOMES, 2005). Essa forma de abordagem também pode ser pensada para as análises do golpe e a ditadura instalada em 1964. A fórmula que apresenta um governo opressor contra uma sociedade oprimida já não é possível. Estudos recentes sobre a temática, com interpretações destacando os enlaces e apoios, começam a ser apresentados pela historiografia (ROLLEMBERG, QUADRAT, 2010).

A análise realizada por René Dreifuss, ainda na década de 1980, era que o Golpe de 1964 seria resultante de um trabalho bem articulado por segmentos de várias organizações e setores sociais, capital internacional, empresários nacionais, intelectuais, militares, movimentos femininos, Igreja Católica e partidos políticos, entre outros setores (DREIFUSS, 2006). Mais recentemente, o historiador Daniel Aarão Reis analisou o Golpe de 1964 também como um movimento construído por complexos segmentos civis e militares. É dentro dessa compreensão que passamos a problematizar a atuação política destes personagens (REIS FILHO, 2005).

Neste sentido, trata-se de considerar que já não cabe individualizar culpados e localizar em suas ações as justificativas para o Golpe. A construção de um discurso de acusação, entretanto, deve ser analisada com mais cuidado. É nesta perspectiva que a trajetória de Paulo Wright foi estudada, levando-se em consideração que atuava numa sociedade em que amplos setores apoiaram a deposição do presidente João Goulart pelos militares. É diante desse cenário que a intensa atuação do citado personagem não encontra mais legitimidade política e social, culminando com a clandestinidade e o exílio. 


\section{A repressão em curso}

Na segunda parte do texto procuramos analisar, de maneira breve, as reações da Igreja Presbiteriana do Brasil na cidade de Florianópolis, em 1964, em relação a um dos seus membros, Paulo Stuart Wright. Fomos motivados, em grande medida, pelas informações contidas na Ata $n^{\circ} 1284$ do Conselho da Igreja Presbiteriana de Florianópolis, de 19 de outubro de $1999^{1}$. Este documento versava sobre a restituição de Paulo Wright como membro daquela igreja, após trinta e cinco da sua expulsão.

Assim, este Conselho - composto pelo pastor e os presbíteros $^{2}$ - reportava-se às decisões tomadas no ano de 1964, quando a Igreja recebera documentos provenientes do Comando do $5^{\circ}$ Distrito Naval de Florianópolis acerca da atuação política do então deputado pelo estado de Santa Catarina, Paulo Wright. Em razão dos referidos documentos - segundo consta em Ata - o Conselho, em 1964, resolveu vetar a posse do Sr. Paulo Stuart Wright ao cargo de presbítero, eliminando-o também do rol de membros efetivos daquela comunidade religiosa ${ }^{3}$.

Eis que em 1999 o vigente Conselho da Igreja Presbiteriana de Florianópolis reavaliou a decisão pondo em evidência que não se fez respeitar o direito a um processo legal, com os benefícios da ampla defesa e do contraditório, e esclareceu que na ausência de tais garantias constitucionais nenhuma sentença poderia haver sido proferida nem executada, com base no artigo 16 do Código de Disciplina da IPB que assegura que "nenhuma sentença será proferida sem que tenha sido assegurado ao acusado o direito de defesa". Associado a isso, "se o acusado for revel e não tiver apresentado defensor, o presidente nomeará pessoa considerada crente para defendê-lo", conforme versa o artigo $59^{4}$. Ao mesmo tempo apresentou que a ausência de Paulo Wright ao julgamento ocorreu devido a seu desaparecimento em virtude do estado de exceção vivenciado no país. E concluiu que o órgão conselheiro da referida igreja era composto por homens crentes e de vida perfeita, mas juridicamente leigos, e que, além disso, tal decisão fora tomada em momento de repressão, o que provocava medo e insegurança na sociedade brasileira ${ }^{5}$. Com esses argumentos, o Conselho da Igreja Presbiteriana de Florianópolis de 1999 justificou as ações tomadas pelo Conselho daquela igreja de 1964 retirando de seus pares quaisquer possibilidades de que a expulsão assumisse alguma conotação política, ainda que efetivada em cooperação com os militares. Entendendo o ocorrido como falhas processuais decorrentes da falta de experiência jurídica e associada ao medo decorrente das circunstâncias do momento. Assim, que o réu, ausente, foi considerado revel sem sequer haver sido citado segundo determina o Código de Disciplina ${ }^{6}$. 
Também ficou registrado que se Paulo Wright estivesse presente em seu julgamento e apresentado sua defesa, sua expulsão tanto poderia haver sido evitada como considerada legítima e justa, pois as formalidades legais haveriam sido cumpridas. Neste sentido, a reparação post mortem de Paulo Wright revelou-se mais em função de supostos erros formais cometidos no processo, levado este a cabo por homens considerados perfeitos e crentes, evidenciando-se assim uma maneira muito particular de a instituição - construída como representação da vontade e da verdade divina na terra - interagir com seu passado, em dado momento de mobilização nacional de políticas de reparações ${ }^{7}$.

A maneira como essa instituição ressignificou seu passado frente às questões postas em 1999 é registrada no jornal Diário Catarinense, um dos principais periódicos em circulação em Santa Catarina. Este afirmou que houve, por parte do Comitê Catarinense PróMemória dos Mortos e Desaparecidos Políticos, pressão para que a Igreja Presbiteriana de Florianópolis oficializasse aquele ato ${ }^{8}$.

De acordo com Derlei Catarina De Luca, que à época da reparação era presidenta do Comitê, os caminhos percorridos para conseguir que a Igreja Presbiteriana em Florianópolis realizasse esta reparação se revelaram tortuosos. Afirmou que em uma tarde chuvosa conversou com o Bispo Auxiliar da Igreja Católica de Florianópolis, Dom Vitor Schlikman, e que este encarregou um sacerdote que mantinha contatos com a Igreja Presbiteriana para tratar sobre o assunto, mas que, segundo Derlei, a instituição só se posicionou positivamente quando o jornalista Moacir Pereira, a pedido daquele bispo, escreveu em sua coluna - mantida em um dos periódicos do Estado de Santa Catarina - a seguinte provocação: “Amigos de Paulo Wright procuram a revisão de ato de exclusão da Igreja Presbiteriana"`.

Paulo Wright era filho dos missionários norte-americanos Latham Sphais Wright e Maggir Belle e nascido em Herval, distrito de Joaçaba, no estado de Santa Catarina, aos 02 de junho de $1933^{10}$. Seus pais haviam sido enviados pela Igreja Presbiteriana dos EUA para trabalhar em cooperação com a IPB. A dupla nacionalidade de Paulo Wright contribuiu para sua formação em ciências sociais pela Universidade da Carolina do Sul, nos EUA. De volta ao Brasil, na década de 1950, passou a escrever artigos para a revista Mocidade defendendo a necessidade de o jovem evangélico desenvolver consciência política e crítica em relação à responsabilidade social da Igreja, sobretudo face à realidade de pobreza que atingia a maior parte da população do país. Atuou como Secretário-geral da União Cristã de Estudantes Brasileiros (UCEB), participando também da Associação Cristã de Acadêmicos (ACA). Passou ainda a manter intenso diálogo com setores da Igreja Católica Romana, como a 
Juventude Universitária Católica (JUC); além disso, foi professor da Escola Dominical ${ }^{11}$ após sua ida para a capital Florianópolis, em 1960 (PAEGLE, 2001, p. 122-127; 2006. p. 148-157).

A visão teológica de Paulo Wright associava-se à de um segmento presbiteriano que propugnava - especialmente a partir da década de 1950 - por maior envolvimento da igreja nos problemas sociais e políticos do país. Sobre esta perspectiva teológica, o pastor presbiteriano e missionário norte-americano Richard Shaull, que naquele período atuava no Brasil e que também participou daquela Conferência, escreveu:

No final dos anos 50 Paulo retornou ao Brasil, depois de abandonar os seus estudos universitários nos Estados Unidos. Logo depois, procurou-me para expressar a sua visão e compromisso [...]. Desde o nosso primeiro encontro percebi que estava diante de alguém apaixonadamente comprometido a seguir com Jesus com absoluta certeza de uma total dedicação à luta pelos pobres. De fato, não havia visto antes ninguém que levasse tão a sério os ensinamentos de Jesus e se dedicasse a pô-los em prática (SHAULL, 2003, p. 153-154).

Neste fragmento Richard Shaull apresenta uma breve exposição acerca de qual era, do seu ponto de vista, a perspectiva teológica de Paulo Wright quando o conheceu. Para Richard, Paulo Wright buscava desenvolver o entendimento de que a Igreja deveria assumir posição de enfrentamento em relação às péssimas condições sociais da maior parte da população no Brasil. Esta tem sido uma memória frequentemente difundida sobre Paulo Wright, com atuação política e teológica construída como estando sempre a serviço dos mais pobres ${ }^{12}$.

Em 1960, Paulo Wright adquiriu experiência política ao disputar, sem sucesso, o cargo de prefeito da cidade de Joaçaba pelo Partido Trabalhista Brasileiro (PTB). Neste mesmo ano mudou-se para Florianópolis e pouco tempo depois foi nomeado diretor da Imprensa Oficial do Estado de Santa Catarina (IOESC). Em outubro de 1962 foi eleito deputado estadual, dessa feita pelo Partido Social Progressista (PSP), com 2.144 votos (PAEGLE, 2001, p. 123). De acordo com Márcio Moreira Alves, essa filiação política, em 1962, representava uma antítese bizarra $^{13}$, tendo em vista seu trabalho na defesa dos pescadores, que se encontravam na dependência dos atravessadores, chamados, naquela região, de pombeiros. Segundo o autor, com o apoio de Paulo Wright foi fundada a FECOPESCA - Federação das Cooperativas de Pescadores - atendendo aproximadamente a quatro mil pescadores. Como deputado estadual passou a defender na tribuna os interesses daquela classe e sua organização, introduzindo mudanças significativas nas relações comerciais anteriormente existentes, o que contrariou as pretensões de grupos econômicos interessados no controle das mesmas (ALVES, 1968, p. 118-120). 
É muito provável que sua atuação política tenha provocado uma série de conflitos na Assembleia Legislativa e na Igreja Presbiteriana de Florianópolis. A este respeito, Jaime Wright, que naquele momento era missionário da Missão Presbiteriana do Brasil Central, ligada à Igreja Presbiteriana dos EUA, afirmou que o discurso político de seu irmão Paulo Wright incomodava os antigos chefes políticos do Estado, sendo também bastante combatido pela liderança da Igreja em Florianópolis. Na visão de Jaime, tal postura política foi considerada de vanguarda, havendo isso provocado a cassação de seu mandato na Assembleia Legislativa assim como sua expulsão da igreja (PAIXÃO JUNIOR, 2000; AQUINO, 2003, p. 27-47). A decisão da expulsão pelo Conselho foi baseada no Código de Disciplina da IPB, em seu artigo 09, referente às penalidades, "que consiste em eliminar o faltoso da comunhão da Igreja. Esta pena só pode ser imposta quando o faltoso se mostra incorrigível e contumaz"14. Paulo Wright foi assim excomungado, condição que lhe impedia de ser designado para realizar orações durante os trabalhos religiosos e também de participar dos sacramentos do pão e do vinho, realizados para lembrar a morte e ressurreição de Jesus Cristo. Este era um sinal bastante visível perante toda a comunidade religiosa de que tal pessoa estava impura aos olhos de Deus e da autoridade da Igreja, que neste contexto é o Conselho.

Considerando inúmeros discursos de protestantes e católicos, a jornalista Marcia Aquino analisou o posicionamento político e teológico de Paulo Wright naquele momento; para tanto procurou manter como eixo central a vida política e teológica, as circunstâncias da prisão, tortura, morte e desaparecimento do ex-deputado das dependências do Departamento de Operações Internas (DOI) - Centro de Operações de Defesa Interna (CODI) ${ }^{15}$ de São Paulo, em 1973- (órgão criado pelo II Exército e comandado entre 1970 e 1974 pelo Cel. Carlos Alberto Brilhante Ustra) ${ }^{16}$. Seguindo seu objetivo, Marcia Aquino publicou as memórias do pastor presbiteriano e doutor em História pela Universidade Presbiteriana Mackenzie, Osvaldo Henrique Hack, para quem, Paulo Wright:

Tinha se envolvido demais politicamente, ideologicamente, e que a igreja não deveria entrar por este lado. Pela definição porque a Igreja Presbiteriana tem uma posição apolítica, como igreja. Ela permite que seus membros participem de política, se candidatem, discutam política. Eu, pessoalmente posso me posicionar, mas a Igreja em si, não. Essa foi a dificuldade: porque o Paulo, como presbítero da igreja, envolveu a igreja. Foi o mesmo problema que ele teve em Joaçaba. Ele envolveu a igreja de Joaçaba (AQUINO, 2003, p. 56-57).

É importante registrar que este foi um discurso de alguém que foi pastor da Igreja Presbiteriana de Florianópolis pouco tempo depois da expulsão de Paulo Wright, entre os 
anos de 1966 e 1992, recebendo desta Igreja o título de pastor Emérito. Neste fragmento, defendeu categoricamente que a Igreja Presbiteriana do Brasil tinha posição apolítica e que a Igreja em Florianópolis - que em 1964 teve como pastor e presidente do Conselho Eny Luz de Moura - vinha entrando em choque com a posição política assumida pelo deputado estadual. E mesmo afirmando não saber detalhes da posição do Conselho no momento da expulsão, lembrou que Paulo Wright era polêmico em suas ideias e muito livre no pensar. Sua posição caminhava na contramão do que deveria ser um presbítero ou qualquer outra pessoa ligada à Igreja.

Quando é eleito, assume o compromisso de respeitar os estatutos e o código de disciplina da Igreja. Todo o envolvimento dele - pessoal, familiar, social, comunitário - tem que refletir as convicções e aquilo que a Igreja considera e acha que é razoável e o mais correto (AQUINO, 2003, p. 52).

Mesmo se construindo essa pessoa polêmica, segundo alguns, isto não impediu que aos 08 de março de 1964 o deputado Paulo Wright fosse eleito presbítero junto a outros dois membros, como consta em Ata:

Foram então eleitos presbíteros da Igreja Presbiteriana de Florianópolis os irmãos Dr. Hurí Gomes Mendonça com trinta e seis votos; Arony Natividade da Costa com vinte e oito votos e Dr. Paulo Stuart Wright com vinte e dois votos. Ao término da reunião foram os presbíteros Dr. Hurí Gomes Mendonça e Dr. Paulo Stuart Wright agradecendo a honra que lhe emprestara ${ }^{17}$.

Como posteriormente descrito na Ata do Conselho da Igreja Presbiteriana de Florianópolis de 19 de outubro de 1999, Paulo Wright foi impedido de assumir o cargo de presbítero para o qual havia sido democraticamente eleito. O historiador Eduardo Paegle analisou em artigos aspectos da atuação política e religiosa de Paulo Wright e afirmou que os dois outros presbíteros que com ele foram eleitos - Hurí Gomes Mendonça e Arony Natavidade da Costa - tiveram seus nomes confirmados e foram devidamente empossados pelo Conselho da igreja algum tempo depois. Mas com Paulo Stuart Wright foi diferente: ele não teve direito à posse, não havendo sido respeitada a vontade da comunidade religiosa que o elegeu, além de em seguida haver sido, pelo mesmo Conselho, expulso do rol de membros da Igreja (PAEGLE, 2001, p. 122-127).

A decisão quanto à não homologação do exercício de presbiterato e expulsão do rol de membros efetivos ocorreu quando o Conselho da Igreja recebeu um dossiê proveniente do $5^{\circ}$ Distrito Naval daquela capital ${ }^{18}$, que estava sob o comando do almirante Murilo Vasco do Vale Silva. O referido dossiê - produzido pela Comissão de Averiguação Sumária, nomeada 
por este Almirante aos 15 dias do mês de abril de 1964 - composto também com acusações provenientes da Secretaria de Segurança Pública ${ }^{19}$, foi encaminhado ao presidente da Assembleia Legislativa do Estado de Santa Catarina (ALESC) em 04 de maio de 1964, e alertava sobre a perigosa posição política do deputado Paulo Wright. Essa documentação foi também utilizada na Assembleia para efetivar a cassação dos direitos políticos de Paulo Wright em 09 de maio de $1964^{20}$. Este dossiê foi recebido pela Igreja Presbiteriana de Florianópolis e registrado na $\operatorname{Ata} n^{\circ}$ 910, referente à reunião Ordinária do Conselho em 13 de maio de 1964. Nesta Ata foi reproduzida parte significativa do ofício $\mathrm{n}^{\circ} 0525$, em que o $5^{\circ}$ Distrito Naval informava à ALESC sobre o dossiê que era encaminhado em anexo. No ofício, o deputado era descrito nos seguintes temos:

\begin{abstract}
Cumpre-se informar que o Sr. Deputado Paulo Stuart Wright, dessa Assembleia Legislativa, eleito sob a legenda do PSP, comunista militante, pauta o seu procedimento e atitudes em face dos problemas nacionais, coerentemente com as suas ideias. Está perfeitamente integrado no movimento de transformação pela violência, do regime estabelecido e afirmado na Constituição da República. A linha de ação do Deputado em causa é fato público e notório, que essa Assembleia sobejamente conhece, o que coloca em posição falsa, diante da Lei Eleitoral, da Constituição e da Lei da Segurança. Na documentação anexa, parte do existente nos vários inquéritos e sindicâncias em andamento encontrará V. Excia. elementos que caracterizem as ligações do referido Deputado com agitadores conhecidos, alguns sem ideologia, simplesmente corrompidos pelo poder do dinheiro do povo, criminalmente usado ${ }^{21}$.
\end{abstract}

Paralelamente outros dossiês contra cidadãos comuns, vereadores, deputados e funcionários da ALESC também foram produzidos por essa mesma Comissão de Averiguação Sumária, seguindo as diretrizes do Ato Institucional $\mathrm{n}^{\circ} 1$. No dossiê em que se investigou uma das funcionárias daquela casa legislativa, Elyanne Marinho de Sousa Santos, assim como acerca de quais eram suas relações com o deputado Paulo Wright, foi explicado pela Comissão Militar que o referido parlamentar, embora ligado à Igreja Presbiteriana, inclusive sendo filho e irmão de pastores presbiterianos norte-americanos, sempre foi comunista e envolvido com outros subversivos conhecidos e atuantes. Este dossiê, assim como outros, foi encaminhado para a ALESC, que deveria posicionar-se a respeito ${ }^{22}$.

Tal vinculação direta do referido deputado com a Igreja Presbiteriana de Florianópolis passou a ser amplamente divulgada, podendo isso haver exercido fortes influências no recebimento, discussão e publicação de um fragmento do dossiê na Ata do Conselho daquela igreja, e contribuindo também para que sua expulsão da Igreja ocorresse quase simultaneamente a sua cassação como deputado, uma vez que a Igreja não permitiria em seu 
rol de membros um acusado e condenado por subversão na ALESC, indicando total aproximação e/ou comprometimento com as ações executadas por aquela casa legislativa e pelos militares.

Sobre a cassação, o pastor Osvaldo Hack afirmou que possivelmente haveria agido de modo diferente se estivesse ele à frente da Igreja Presbiteriana em Florianópolis àquela época, entretanto, logo em seguida, justificou tal ação do Conselho daquela igreja afirmando que, naquele caso em particular, houve forte interferência externa proveniente do $5^{\circ}$ Distrito Naval, ou seja, afirmou a existência de uma imposição dos militares capaz de interferir nas decisões do Conselho, impossibilitando assim outras decisões naquele momento (AQUINO, 2003, p. 54). Evidentemente que não podemos perder de vista ser esse um discurso do presente de alguém que representa uma instituição religiosa cuja postura revelou uma sintonia com as práticas do Regime civil-militar de 1964.

Posteriormente, em janeiro de 1965, o Presbitério de Florianópolis, reunido na cidade de Herval D' Oeste, distante da capital 414 km (quatrocentos quilômetros), homologou a posição tomada pelos representantes daquela igreja ${ }^{23}$. Conforme o costume, ao início ou término de cada ano, os presbitérios que compõem a Igreja Presbiteriana do Brasil se reuniam (e ainda o fazem) com, entre seus itens de pauta, o objetivo de examinar e aprovar as inúmeras atas produzidas no exercício findo pelos Conselhos das igrejas locais sob sua jurisdição, dando-lhes o respectivo parecer. Em relatório produzido por uma comissão do Presbitério de Florianópolis, que examinou aquela ata, constam as seguintes considerações:

O Presbitério aprova as atas do conselho da Igreja de Florianópolis com as seguintes observações: a) As atas n. 910 e 911 foram lavradas com caneta esferográfica. Já estão consideravelmente apagadas e em pouco tempo não poderão ser lidas. b) A ata n. 910, folha 104 linha 15 verso é eliminado um membro do rol da igreja, sumariamente, sem ser ouvido, e sob, a acusação, de fora da Igreja, de ser o mesmo comunista. Que o conselho reestude o assunto ${ }^{24}$.

Esse fragmento do relatório afirma que a Igreja Presbiteriana de Florianópolis teve sua ata aprovada, mas com ressalvas, sobretudo no que diz respeito ao caso da expulsão de Paulo Wright. Em entrevista, o professor de História da Igreja e advogado Maely Ferreira Vilela, ao analisar o fragmento acima, afirmou ser possível que os artigos 16 e 59 do Código de Disciplina tenham sido discutidos nesta referida Reunião do Presbitério; esclareceu que tais artigos garantiam que nenhuma sentença pudesse ser proferida sem que ao acusado fosse assegurado o direito de defesa e que, se porventura o acusado não comparecesse ao ser convocado, deveria ser nomeado defensor que o representasse. E, quanto à alegação de que as 
acusações a Paulo Wright não haviam sido produzidas pela Igreja, mas pelo $5^{\circ}$ Distrito Naval, o professor Maely avaliou que o documento levantava um questionamento referente à competência jurídica da matéria, ou seja, que o fato de ser acusado e cassado pela Assembleia Legislativa não se constituía em impedimento para que também fosse punido e responsabilizado perante a Igreja ${ }^{25}$.

O pesquisador Eduardo Guilherme de Moura Paegle declarou algo que consideramos significativo problematizar, afirmou que no documento $\mathrm{n}^{\circ} 57$ a expressão que o Conselho reestude o assunto, sugerida pela comissão examinadora, encontra-se riscada, tendo ao lado e com outra escrita a expressão caiu, indicando assim uma interferência posterior ao texto do relatório, ou seja, uma alteração produzida pelo próprio Presbitério em Assembleia (PAEGLE, 2006, p. 155); com isso, consideramos que a ação do Presbitério de Florianópolis pode haver se efetivado em legitimação à posição assumida pelo Conselho daquela igreja, aprovando a expulsão de Paulo Wright, como indica o termo caiu.

Não se tratou, portanto, de falta de experiência por parte daquele Conselho, como expresso na Ata $n^{\circ} 1284$ de 1999, mas de uma prática na instituição a partir de 1964, quando, muitas vezes, o Código de Disciplina e a Constituição da IPB não eram observados, seja por conveniência, seja por postura autoritária que foi ganhando força na instituição. Ao mesmo tempo, essa posição da IPB encontrava sintonia no próprio ambiente político nacional instituído com o Golpe de 1964.

Para o cientista político Anthony Pereira, neste período - tanto no Brasil como no Cone Sul - o estado de direito estava distante de uma realização plena, onde a lei nem sempre era o que parecia ser e os réus eram condenados apenas por suas convicções políticas, ou seja, as leis eram vagas e permitiam condenações sobre qualquer tipo de comportamento. Durante o Regime Militar, os processos judiciais estavam em sintonia com o estado de direito em aparência, muito embora nem sempre em substância (PEREIRA, 2010, p. 54).

A Igreja em Florianópolis, assim como seu Presbitério, desenvolveu práticas semelhantes aos órgãos de vigilância e repressão do Estado. Ao expulsar Paulo Wright tendo como referência as acusações produzidas pelos organismos de repressão, atuou reconhecendo e legitimando a vigilância e as punições praticadas pelo Regime militar; dessa maneira, concorreu para legitimar as leis que o enquadravam como personagem perigoso para o país e, neste caso, perigoso também para a Igreja - de acordo com o recém-implantado Ato Institucional $\mathrm{n}^{\circ} 1$ e a Lei de Segurança Nacional de 1953: leis expressas tanto no dossiê enviado para a Igreja pelo $5^{\circ}$ Distrito Naval citado anteriormente quanto no Parecer da 
Comissão de Constituição, Legislação e Justiça, assim como também no Diário da Assembleia do Estado de Santa Catarina quando publicou, no dia 14 de maio, a Resolução 85/64, que cassou em definitivo os direitos políticos do deputado Paulo Stuart Wright, nos termos a seguir:

\begin{abstract}
Resolve - Art.1. - Fica, na conformidade que dispõe a Constituição do Estado de Santa Catarina, combinado com o Ato Institucional, por infringência de dispositivos previstos na Lei $\mathrm{n}^{\circ} 1.802$, de 5 de janeiro de 1953 , que define os crimes contra o Estado e a ordem Política e Social, bem como o art. 141, \& $5^{\circ}$, parte final, da constituição Federal, Cassado o Mandato do Senhor Deputado Paulo Stuart Wright, eleito em 6 de outubro de 1962, sob a Legenda do Partido Social Progressista (P.S.P.). Art. 2. - Esta Resolução entrará em vigor da sua publicação, resguardada as disposições em contrário ${ }^{26}$.
\end{abstract}

A partir da resolução, os pares do deputado Paulo Wright na Assembleia Legislativa recorreram ao artigo 10 do Ato Institucional $n^{\circ} 1$, promulgado aos 09 de abril de 1964, que garantia a suspensão dos direitos políticos por até dez anos. Entretanto, de acordo com este artigo, esta era uma prerrogativa apenas do chefe do Executivo, que poderia cassar mandatos legislativos federais, estaduais e municipais. Com este poder, segundo Thomas Skidmore, até 15 de julho, data limite para a expiração do temido artigo 10, o governo militar havia cassado os direitos políticos de 378 cidadãos $^{27}$. Da perspectiva de análise de Anthony Pereira, nos primeiros anos do regime militar, o governo recorreu à Lei 1802/53 como base legal para a instauração de processos contra aqueles que eram acusados de serem comunistas e defensores do governo de João Goulart (PEREIRA, 2010, p. 88).

Delora Jan Wright, autora do livro $O$ coronel tem um segredo, ao comentar aspectos da vida de Paulo Wright, declarou que o processo de cassação do seu tio foi acelerado após um telegrama do então Secretário do Conselho Nacional de Segurança, o Gal. Ernesto Geisel, protestante de confissão luterana. Segundo ela, em 09 de maio de 1964, em um tempo considerado curto para tramitar e julgar esse tipo de processo político, as bancadas dos partidos fizeram suas declarações de voto e pronunciaram-se a favor de sua cassação, inclusive a do partido ao qual Paulo estava filiado, o PSP. Assim, que...

A Bancada da União Democrática Nacional declara que votou favoravelmente ao parecer da Comissão de Justiça, declarando vago o mandato do Sr. Deputado Paulo Stuart Wright, entre outras, pelas seguintes razões: 1) Demonstradas estão as ligações do referido deputado com elementos reconhecidamente subversivos. a) $\mathrm{O}$ Partido Trabalhista Brasileiro, em convenção realizada para organizar as listas de candidatos a deputado em 1962, resolveu excluir o nome do Sr. Paulo Wright, já naquela época conhecido como integrante da extrema esquerda. b) O Partido Social Progressista, que acolheu na sua legenda e permitiu a eleição do Sr. Paulo Wright, expulsou-o tão logo tomou conhecimento das suas ligações com o comunismo. c) Pregou, na tribuna da Assembleia, nos comícios e nos sindicatos, as mesmas ideias 
do conhecido agitador padre Alípio de Freitas e dos ex-deputados Leonel Brizola, Max da Costa Santos, Neiva Moreira e outros elementos ligados à subversão. d) $\mathrm{O}$ 'dossiê' da Secretaria da Segurança Pública e as averiguações sumárias procedidas pelo Comando Militar trazem provas suficientes para dar cobertura ao óbvio, que de prova não necessitava (WRIGHT, 1993, p. 42-45).

Cassado pela Assembleia Legislativa, expulso da Igreja Presbiteriana de Florianópolis e prevendo que seria preso a qualquer momento, diante da conjuntura política que se apresentava, Paulo Wright optou por refugiar-se na Embaixada do México, na cidade do Rio de Janeiro ${ }^{28}$, país para onde partiu pouco tempo depois, tendo outros brasileiros em situação semelhante, a exemplo de seu amigo, Pe. Alípio de Freitas ${ }^{29}$. Em seguida Paulo viajou para Cuba, onde realizou inúmeras palestras e contatos políticos. Na segunda metade de 1965 voltou clandestinamente ao Brasil - adquirindo, a partir de então, outras identidades - e passou a integrar os quadros da Ação Popular (AP), tornando-se um de seus principais líderes. Embora procurado pelas forças de repressão, conseguiu - com ajuda de amigos e setores ecumênicos (católicos e protestantes) - manter sua atividade política até setembro de 1973, quando foi preso na cidade de São Paulo por agentes do Departamento de Operações Internas - Centro de Operações de Defesa Interna (DOI-CODI). Após essa prisão não se soube/sabe indicar qual seu paradeiro, estando seu corpo, até o momento, desaparecido (WRIGHT, 1993, p. 95-118).

\section{Considerações finais}

Paulo Wright não atuou no processo de redemocratização política do Brasil, a exemplo de tantos outros ex-exilados, mas sua trajetória possibilita problematizar como inúmeros membros e pastores ligados à Igreja Presbiteriana do Brasil tiveram, a partir de 1964, suas práticas políticas e religiosas questionadas e investigadas pelos órgãos de repressão e informação do Estado ditatorial e/ou pela própria Igreja Presbiteriana do Brasil, vivenciando situações várias em que eram denunciados por representantes de suas próprias paróquias aos órgãos de informação e segurança e levados a antecipar a prestação de esclarecimentos às autoridades policiais na tentativa de evitar suas prisões. Ao mesmo tempo, os militares acompanhavam atentamente o comportamento e as ações de inúmeros membros das igrejas e pastores presbiterianos, muitas vezes denunciando-os às autoridades eclesiásticas na expectativa de que a Igreja tomasse determinadas providências. Considerado o contexto político nacional da situação, os militares, setores da IPB e a Assembleia Legislativa do 
Estado de Santa Catarina atuaram conforme um espírito de cooperação e comprometimento vigente. Cumprido este objetivo, além da troca de informações e em razão de uma possível ameaça ao Brasil, expulsaram Paulo Wright da Igreja e da Assembleia Legislativa quase simultaneamente. Tal foi um período de duradora relação de cooperação e subordinação da Igreja Presbiteriana do Brasil ao Regime Militar.

Analisar a trajetória de Paulo Wright contribuiu, dentro de suas especificidades, para pensarmos a história do Brasil em um momento de implantação de um governo antidemocrático. Sua trajetória apresenta suas escolhas frente às opções apresentadas por uma sociedade que transitava de um regime democrático para uma ditadura em 1964. Assim, foi possível conhecer histórias de vida, mas também dinâmicas sociais e políticas mais amplas. No presente estudo de caso, tal trajetória indica, de modo significativo, como uma sociedade criou uma série de mecanismos de controle e exclusão, retirando da vida pública personagens que antes de 1964 mantinham intensa atuação política no Brasil, além de reconhecidos internacionalmente.

\section{Notas}

${ }^{1}$ Ata do Conselho da Igreja Presbiteriana de Florianópolis, nº 1284, 19/10/99. Arquivo Interno.

${ }^{2}$ É significativo tecer algumas considerações sobre a estrutura administrativa da IPB. As igrejas locais são conduzidas por um Conselho formado por presbíteros e pastor, que é o presidente deste Conselho. Os presbíteros geralmente são pessoas de mais idade que podem ser indicadas pela comunidade ou pelo próprio Conselho, e que só após terem seus nomes aprovados por este Conselho é que são eleitos pela comunidade para um mandato de cinco anos, não havendo, portanto, qualquer restrição em relação ao número de mandatos consecutivos.

${ }^{3}$ Segundo dados extraídos da Estatística do Culto Protestante do Brasil 1967, do Serviço de Estatística Demográfica, Moral e Política, órgão ligado ao Ministério da Justiça, a Igreja Presbiteriana de Florianópolis contava, em 1966, com um quantitativo de 591 membros, sendo uma das maiores da denominação presbiteriana no estado de Santa Catarina. Muito embora em 1967 a estatística registrasse uma exclusão de 379 membros, sugerindo algum tipo de divisão. Importante lembrar que a Igreja Luterana destacava-se em número de templos e membros naquele estado, assim como em toda a região Sul do Brasil.

${ }^{4}$ Código de Disciplina da Igreja Presbiteriana do Brasil.

${ }^{5}$ Ata do Conselho da Igreja Presbiteriana de Florianópolis, $n^{\circ}$ 1284, 19/10/99. Ver também Resolução da Igreja Presbiteriana de Florianópolis: restauração post mortem de condição de membro de Igreja Paulo Stuart Wright 19/10/1999. Arquivo Interno.

${ }^{6}$ De acordo com o Código de Processo Civil, que é fonte subsidiária do Código de Disciplina da IPB, "torna-se revel o réu que não responder à ação quando regularmente citado. Assim, revelia é a ausência de defesa do réu. Revel é aquele que devidamente citado não se contrapõe ao pedido formulado pelo autor. Ele permanece inerte e não responde à ação. Neste caso os fatos afirmados pelo autor presumem-se verdadeiros, porém esta presunção de veracidade não é absoluta". Disponível em: <http://www.direitonet.com.br/dicionario/exibir/927/Revel $>$. Acesso em: 30 dez. 2012.

${ }^{7}$ A este respeito, a historiadora Maria Paula Araújo afirmou que, "em nosso mundo contemporâneo, nas últimas décadas, inúmeras sociedades tiveram transições políticas importantes: passaram de regimes ditatoriais e arbitrários para regimes democráticos. Em todos esses casos uma questão se colocou para a sociedade e para o Estado, logo após (e, muitas vezes durante) o processo de consolidação democrática: o que fazer com a herança 
autoritária? [...] Cada país adota diferentes medidas de 'justiça de transição' - de acordo com sua história, sua cultura política e a correlação de forças da época da transição. A justiça de transição implica algumas questões: direito à memória, apuração da verdade, promoção da justiça, reconciliação nacional, reparação das vítimas". (ARAÚJO, 2012, p. 54-55).

${ }^{8}$ PRESBITERIANOS revogam punição a Paulo Wright. Jornal Diário Catarinense, Florianópolis, 03 nov. 1999.

9 Email enviado por Derlei De Luca em 08 de janeiro de 2013 . Disponível em: <HTTP://sn110w.snt.mail.live.com/mail/PrintMessagens.aspx?cpids=420863f4-59eb-1>.

${ }^{10}$ Rio Grande do Norte/Secretaria de Estado do Interior e Segurança/DOSP/RGN. Arquivo Público do Estado do Rio Grande do Norte, cód.ref. BR RNAPERN, XX DO. 0 FC.1563. Memórias Reveladas - Centro de referência das lutas políticas no Brasil (1964-1985).

11 Horário destinado às atividades de educação religiosa, promovidas pela maioria das igrejas evangélicas/protestantes, que ocorre geralmente aos domingos, no turno da manhã.

${ }^{12}$ Têm sido recorrente essas memórias acerca de Paulo Wright, sobretudo entre familiares e pessoas que com ele conviveram ou mantiveram algum contato. Perspectiva bem presente no livro de WRIGHT, Jan Delora. $O$ coronel tem um segredo: Paulo Stuart Wright não está em Cuba. Petrópolis: Vozes, 1993.

${ }^{13}$ Por este termo é possível que Márcio Moreira Alves estivesse apontando para certa concepção política que norteava o PSP naquele momento. De acordo com o Dicionário Histórico, o Partido Social Progressista foi criado em 1946 por Ademar de Barros, ex-interventor, atuante durante o Estado-Novo em São Paulo, partido que possuía forte viés clientelista. No inicio da década de 1960 rompeu com o presidente João Goulart, colocando-se na oposição, sobretudo no que diz respeito às questões da Reforma Agrária, fazendo vistas grossas à conspiração que se armou em São Paulo contra Jango, estreitando suas relações com bases mais tradicionais da política e da sociedade. Dicionário Histórico-Biográfico Brasileiro pós-1930, Coordenação: Alzira Alves de Abreu ... [et al.]. Rio de Janeiro: Editora FGV; CPDOC, v. IV, 2001. p. 4401-4407.

${ }^{14}$ Código de Disciplina da Igreja Presbiteriana do Brasil.

${ }^{15}$ De acordo com Carlos Fico, os CODIs eram órgãos destinados ao planejamento e coordenação das medidas de defesa interna. Os DOIs eram unidades militares destinadas às ações de repressão: prisão e interrogatório, ou, como afirmou o autor, eram designados para o "trabalho sujo". Ambos estavam sob o comando do Exército (FICO, 2001, p. 115-135).

${ }^{16} \mathrm{O}$ coronel Brilhante Ustra teve sua condenação - como torturador durante o regime militar - confirmada pelo Tribunal de Justiça de São Paulo em 2012. A condenação foi referente às torturas sofridas por três pessoas presas em 1972, durante o período em que o coronel comandou o DOI-CODI de São Paulo (1970-1974). E sob seu comando ocorreram inúmeros casos de torturas e mortes de presos políticos. Disponível em: http://veja.abril.com.br/noticia/brasil/justica-de-sao-paulo-reconhece-ustra-como-torturador-durante-regime-

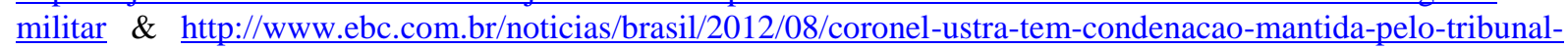
de-justica-de-sao-paulo. Acessados em: 10 maio 2013.

${ }_{17}$ Ata do Conselho da Igreja Presbiteriana de Florianópolis. Livro 09, n 910, 08/03/64, pp. 103-104. Arquivo Interno.

${ }^{18}$ Ver Ata do Conselho da Igreja Presbiteriana de Florianópolis, n ${ }^{\circ}$ 1284, 19/10/99. Arquivo Interno.

${ }^{19}$ Copia deste e de outros dossiês compõem o Inquérito Policial Militar/IPM n ${ }^{\circ} 709$. Documentação localizada no arquivo digital Brasil: Nunca Mais, pasta 279. Disponível em: 〈http://bnmdigital.mpf.mp.br/\#!/>. Acesso em: 28 ago. 2013. É importante ressaltar que, segundo Derlei De Luca, em 1985, quando a ALESC decidiu revogar a resolução 85/64, que cassou os direitos políticos de Paulo Wright, foi autorizada a abertura de um cofre onde estaria guardado o referido dossiê. Afirmou Derlei que, para surpresa de todos, a documentação não se encontrava lá, causando isso estranheza, o que foi noticiado na época pela imprensa de Santa Catarina.

${ }^{20}$ Documentação da Assembleia Legislativa do Estado de Santa Catarina/ALESC, gentilmente cedida por Derlei De Luca. Arquivo pessoal.

${ }^{21}$ Ata do Conselho da Igreja Presbiteriana de Florianópolis. Livro 09, n 910, p. 104. Arquivo Interno. O ofício $\mathrm{n}^{\circ}$ 0525, intitulado: Atividades subversivas do Sr. Deputado Paulo Wright, foi localizado no arquivo digital Brasil: Nunca Mais, pasta 279, pp. 17344-17345. Disponível em: http://bnmdigital.mpf.mp.br/\#!/. Acesso em: 28 de agosto de 2013. 


\footnotetext{
${ }^{22}$ Documentação cedida por Derlei De Luca. Sobre esses e outros dossiês ver também o arquivo digital Brasil: nunca mais.

${ }^{23}$ Os presbitérios são formados por representantes dos conselhos das igrejas locais mais os pastores. Em cidades grandes, é comum existirem vários presbitérios, como também, um presbitério pode ser formado com igrejas de várias cidades. Reúnem-se ordinariamente ao início de cada ano.

${ }^{24}$ Documento $\mathrm{n}^{\circ}$ 57. Arquivo interno do Presbitério de Florianópolis. Este documento também foi publicado por PAEGLE, 2006, p. 155.

${ }^{25}$ Maely Ferreira Vilela, advogado e pastor presbiteriano, foi entrevistado na cidade do Recife, Pernambuco, em 28 de dezembro de 2012, pelo pesquisador Márcio Vilela Formado em teologia pelo Seminário Presbiteriano do Norte/Recife, tornando-se posteriormente professor da disciplina de História da Igreja. Em 2002 foi nomeado diretor do Seminário Teológico do Nordeste na cidade de Teresina, atividade que exerceu até 2012.

${ }^{26}$ Diário da Assembleia do Estado de Santa Cantarina, Florianópolis, 14 de maio de 1964, p. 21.

${ }^{27}$ O historiador Thomas Skidmore esclarece que com o AI-1, elaborado por Francisco Campos, o Comando Revolucionário (o general Artur da Costa e Silva, o tenente-brigadeiro Francisco de Assis Correia de Melo e o vice-almirante Augusto Hamann Rademaker Grünewald) incorporava poderes para estabelecer o estado de sítio sem aprovação do Congresso Nacional (SKIDMORE, 1982, p. 372-373).

${ }^{28}$ Em 12 de maio de 1964 solicitou asilo político na Embaixada do México no Rio de Janeiro, recebendo salvoconduto para deixar o Brasil em 02 de junho do mesmo ano. E retorna clandestinamente ao Brasil no ano seguinte, passando a participar da organização e deflagração da luta armada contra o Regime Militar. Lista de Asilados Políticos. Pasta Asilo Político - III 2904-8. Secretaria de Relaciones Exteriores - SRE. México D.F.

${ }^{29}$ Nascido na cidade de Bragança, em Portugal, o padre Alípio de Freitas chegou ao Brasil em 1957, onde passou a desenvolver uma série de atividades junto à Juventude Operária Católica, à Ação Católica Operária e à organização das Ligas Camponesas no Norte e Nordeste. Em 05 de abril de 1964 requereu exilo político na Embaixada do México, retornando clandestinamente ao Brasil no ano seguinte e passando a participar da organização e deflagração da luta armada contra o Regime Militar (FREITAS, 1981).
}

\section{Referências bibliográficas}

ALVES, Márcio Moreira. O Cristo do povo. Rio de Janeiro: Editora Sabiá, 1968.

AQUINO, Marcia Elizabeth de. Personas: gradações do discurso político-religioso no Brasil pós-64. São Paulo: M. E. de Aquino, 2003.

ARAÚJO, Maria Paula. Uma história oral da Anistia no Brasil: memória, testemunho e reparação. In: MONTENEGRO, Antonio Torres; RODEGHERO, Carla Simone; ARAÚJO, Maria Paula (Orgs.). Marcas da Memória: história oral da Anistia no Brasil. Recife: Ed. Universitária da UFPE, 2012.

DREIFUSS, René Armand. 1964: a conquista do Estado: ação política, poder e golpe de classe. $6^{\circ}$.edição. Petrópolis-RJ: Vozes, 2006.

FICO, Carlos. Como eles agiam: os subterrâneos da ditadura militar: espionagem e polícia política. Rio de Janeiro. Record, 2001. p. 115-135.

FREITAS, Alípio de. Resistir é preciso. Rio de Janeiro: Record, 1981.

FURTADO, Celso. A fantasia desfeita. $3^{\mathrm{a}}$ edição. Rio de Janeiro: Paz e Terra, 1989. p. 119.

GASPARI, Elio. A ditadura envergonhada: as ilusões armadas. São Paulo: Ed. Companhia das Letras, 2002.

GOMES, Angela de Castro. A invenção do trabalhismo. $3^{\text {a }}$ Ed. Rio de Janeiro. Ed. FGV, 2005.

LOWY, Michael. Eric Hobsbawm, sociólogo do milenarismo campesino. In: Revista Estudos Avançados 69. Universidade de São Paulo. Instituto de Estudos Avançados. Vol. 24, n 69, maio-ago. 2010. p. 114. 
PAEGLE, Eduardo Guilherme de Moura. Entre a cruz e a espada: os aspectos biográficos da vida de Paulo Stuart Wright. Protestantismo em Revista, São Leopoldo, v. 26, p. 122-127, set./dez. 2001.

. A posição política da Igreja Presbiteriana do Brasil (IPB) nos anos de chumbo (1964-1985). Dissertação (Mestrado em História) - Centro de Filosofia e Ciências Humanas, Universidade Federal de Santa Catarina, Florianópolis, 2006. p. 148-157.

PAIXÃO JUNIOR, Valdir Gonzales. A era do trovão: poder e repressão na Igreja Presbiteriana do Brasil no período da ditadura militar (1966-1978), Dissertação (Mestrado em Ciências da Religião) - Universidade Metodista de São Paulo, São Paulo, 2000.

PEREIRA, Anthony W. Ditadura e repressão: o autoritarismo e o estado de direito no Brasil, no Chile e na Argentina. São Paulo: Paz e Terra, 2010.

REIS FILHO, Daniel Aarão. Ditadura militar, esquerdas e sociedade. Rio de Janeiro: Jorge Zahar Ed., 2005.

ROLLEMBERG, Denise. Exílio: entre raízes e radares. Rio de Janeiro: Record, 1999.

ROLLEMBERG, Denise; QUADRAT, Samantha Viz (Org.). A construção social dos regimes autoritários. Legitimidade, consenso e consentimento no século XX. Rio de Janeiro: Civilização Brasileira, 2010.

SARZYNSKI, Sara. Ressurecting Canudos and Revolutionizing Jesus: Religous symbols and rural social activism in Northeasttern Brazil. Paper presented at New York City Latin American History Workshop. 28 jan. 2011.

SHAULL, Richard. Surpreendidos pela graça. Memórias de um teólogo: Estados Unidos, América Latina, Brasil. Rio de Janeiro: Record, 2003.

SKIDMORE, Thomas. Brasil: de Getúlio Vargas a Castelo Branco, 1930-1964. Rio de Janeiro: Paz e Terra, 1982.

WRIGHT, Jan Delora. O coronel tem um segredo: Paulo Stuart Wright não está em Cuba. Petrópolis: Vozes, 1993.

\section{Fontes}

Diário da Assembleia do Estado de Santa Catarina, Florianópolis, 14 de maio de 1964.

Diário Catarinense, Florianópolis, 03 nov. 1999.

\section{Atas do Conselho da Igreja Presbiteriana de Florianópolis}

Ata do Conselho da Igreja Presbiteriana de Florianópolis, n 1284, 19/10/99.

Ata do Conselho da Igreja Presbiteriana de Florianópolis. Livro 09, n 910, 08/03/64.

Ata do Conselho da Igreja Presbiteriana de Florianópolis. Livro 09, n 910, p. 104.

Resolução da Igreja Presbiteriana de Florianópolis: restauração post mortem de condição de membro de Igreja Paulo Stuart Wright - 19/10/1999.

\section{Entrevistas}

Maely Ferreira Vilela, advogado e pastor presbiteriano, foi entrevistado na cidade do Recife, Pernambuco, em 28 de dezembro de 2012, pelo pesquisador.

\section{Acervos pessoais}


Documentação da Assembleia Legislativa do Estado de Santa Catarina/ALESC, gentilmente cedida por Derlei De Luca. Arquivo pessoal.

\section{Sites}

Arquivo digital Brasil: Nunca Mais, pasta 279. Disponível em: <http://bnmdigital.mpf.mp.br/\#!/>. Acesso em: 28 ago. 2013.

Código de Processo Civil, Disponível
<http://www.direitonet.com.br/dicionario/exibir/927/Revel>. Acesso em: 30 dez. 2012.

“Coronel Ustra tem condenação mantida pelo Tribunal de Justiça de São Paulo”. Disponível em: <http://www.ebc.com.br/noticias/brasil/2012/08/coronel-ustra-tem-condenacao-mantidapelo-tribunal-de-justica-de-sao-paulo.> Acesso em 10 maio 2013

Email enviado por Derlei De Luca em 08 de janeiro de 2013. Disponível em: <HTTP://sn110w.snt.mail.live.com/mail/PrintMessagens.aspx?cpids=420863f4-59eb-1>

"Justiça mantém decisão que reconhece coronel Ustra como torturador". Disponível em: $<$ http://veja.abril.com.br/noticia/brasil/justica-de-sao-paulo-reconhece-ustra-como-torturadordurante-regime-militar >. Acesso em 10 maio 2013.

Ofício $\mathrm{n}^{\circ}$ 0525, intitulado: Atividades subversivas do Sr. Deputado Paulo Wright, foi localizado no arquivo digital Brasil: Nunca Mais, pasta 279, pp. 17344-17345. Disponível em: http://bnmdigital.mpf.mp.br/\#!/. Acesso em: 28 de agosto de 2013. 